\title{
Çocukların Dünya'nın Şekli ve Gece-Gündüz Kavramlarına Yönelik Zihinsel Modelleri $^{1}$
}

\author{
Arş.Grv.Dr. Sinem Güçhan Özgül \\ Balıkesir Üniversitesi-Türkiye \\ sinem@balikesir.edu.tr
}

\section{Prof.Dr. Berrin Akman}

Hacettepe Üniversitesi-Türkiye

bakman@hacettepe.edu.tr

Doç.Dr. Mesut Saçkes

Balıkesir Üniversitesi-Türkiye

msackes@gmail.com

\begin{abstract}
Özet:
Bu çalışma 60-72 aylık çocukların Dünya'nın şekli ve Gece-Gündüz kavramlarına ilişkin zihinsel modellerini ortaya koymak amacıyla yapılmıştır. Araştırmanın çalışma grubunu 2015-2016 eğitim-öğretim yulında Kuzeybatı Anadolu'da bulunan bir büyükşehrin merkez ilçesindeki bir anaokuluna devam eden ve yaşları 60-72 aylar arasında değişen 31 kız 25 erkek toplam 56 çocuk oluşturmaktadır.

Bu araştırmanın amacı kapsamında iç içe karma yöntem yaklaşımına uygun olarak nicel ve nitel veri toplama araçlarından elde edilen veriler birlikte ve nicel olarak analiz edip yorumlanmıştır. Bu araştırmada kullanılan veri toplama araçları "Dünya2 Testi" ve "Dünya ve Gece-Gündüz Görüșme Protokolü"dür.

Araştırmanın bulgularına göre çocukların tümünün Dünya'nın şekli ve gece gündüz kavramlarına ilişkin sentetik zihinsel modellere sahip olduğu görülmektedir. Dünya'nın şekline ilişkin bulgular çocukların büyük çoğunluğunun düzleştirilmiş dünya modeline sahip olduklarını göstermektedir. Bununla birlikte, simit dünya modeli benzer kültürler ve yakın coğrafyalarda yapılan çalışmalarda olduğu gibi bu çalışmada da ortaya çıkmıştır. Gece-gündüz oluşumuna ilişkin bulgular çocukların bu kavramları ve olguları büyük çoğunlukla Güneş'in hareketlerine atfettiklerini, sınırlı sayıda çocuğun ise bu kavramları Allah ile ilişkilendirdiğini göstermektedir.
\end{abstract}

Keywords: Dünya, gece-gündüz, zihinsel modeller

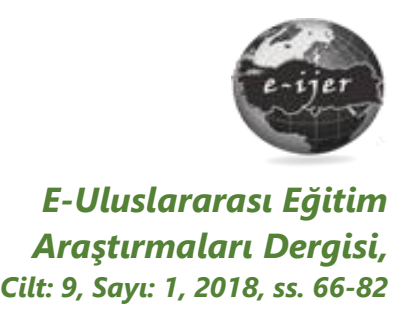

DOI: 10.19160/ijer.379293

Gönderim : 16-01-2018

Kabul : 15-02-2018

\section{Önerilen Atıf}

Özgül, S.G., B. Akman \& M. Saçkes (2018). Çocukların Dünya'nın Şekli ve Gece-Gündüz Kavramlarına Yönelik Zihinsel Modelleri, E-Uluslararası Eğitim Araştırmaları Dergisi, Cilt: 9, Sayı: 1, 2018, ss. 66-82, DOI: 10.19160/ijer.379293

\footnotetext{
${ }^{1}$ Bu çalışma birinci yazarın (Sinem Güçhan Özgül) "Sorgulama Temelli Oyunların Çocukların Dünya'nın Şekli ve GeceGündüz Kavramlarını Algılamalarına Etkisi" başlıklı doktora tez çalışmasından üretilmiştir.
} 


\section{GiRiş}

Çocuklar çevrelerini araştırmaya ve keşfetmeye karşı doğuştan getirdikleri merak ve öğrenme isteği ile donanmışlardır (Akman, Üstün ve Güler, 2003; Eshach \& Fried, 2005; French, 2004; Gelman \& Brenneman, 2004; Mantzicopoulos, Patrick \& Samarapungavan, 2008; Saçkes, Trundle, Bell, \& O'Connell, 2011; Tu, 2006; Wellman \& Gelman, 1998). Erken çocukluk dönemindeki çocuklar merak ederek, araştırarak ve keşfederek tıpkı bilim insanları gibi gözlem, çıkarım, ölçme, sınıflama yaparak ve problem çözerek çevrelerinde bulunan olguları incelemeye heveslidir (Akman, vd., 2003; Eshach \& Fried, 2005; Hayes, Goodhew, Heit, \& Gillan, 2003; Mantzicopoulos vd., 2008; Saçkes, Flevares, \& Trundle, 2010; Saçkes vd., 2011; Trundle \& Saçkes, 2012). Bu sayede özellikle iki ve yedi yaşlar arasında çocuklar binlerce kelimeyi, sayma ve akıl yürütmeyi, diğer insanların duygu ve düşüncelerini okuyabilmeyi, fizik ve biyoloji ile ilgili kavram ve olguları öğrenebilmekte ve yaşamlarının ilk yıllarında şaşırtıcı miktarda ve çeşitlilikte bilgiye sahip olabilmektedirler (Gelman, 2005).

Doğal dünyaya ilişkin üç bilimsel içerik alanından söz etmek mümkündür. Bunlar; fiziki bilim, canlı bilimi ile dünya ve uzay bilimleridir (NRC, 1996). Çocuklar erken yaşlardan itibaren hareket, ışık, ısı gibi fiziki bilimlere ilişkin kavramlar ile canlı-cansız varlıklar ve canlıların yaşam döngüleri gibi olgularla yakından ilgilenirler. Bunların yanı sıra dünya ve özellikle uzayla ilgili konular da çocuklar için şaşırtıcı derecede ilgi çekicidir (Kallery, 2011; Özsoy, 2012; Sackes, 2015; Saçkes, Smith, \& Trundle, 2016). Bu nedenle çocuklar dünyanın ve diğer gezegenlerin fiziksel özellikleri, ay ve güneşin döngüleri ve gece-gündüz oluşumu gibi kavramlara karşı dikkat çekici şekilde merak besleyerek, gözlemler yapmakta, sorular sormakta ve açıklamalar üretmektedirler. Küçük çocukların doğal dünyanın işleyişine yönelik kavramsal anlayışlarının gündelik gözlemlerine dayandığı ve informal öğrenme deneyimleri ile şekillendiği kabul edilmektedir (Hannust \& Kikas, 2007; Kikas, 1998). Araştırmalar çocukların gök cisimleri ve olgularıyla ilgili günlük gözlemleri ve kültürel olarak öğrendiklerini sentezleyerek oluşturdukları açıklamalar ile bilimsel olanlar arasında farklılıklar olduğunu göstermektedir (Hayes vd., 2003; Saçkes, 2015; Vosniadou \& Brewer, 1992, 1994). Ampartzaki ve Kalogiannakis (2016) bu farklılıkların nedenini:

- Çocukların yerçekimi kurallarına ilişkin temel anlayışlarının yetersiz olması (Sneider \& Ohadi, 1998)

- Çocukların gök cisimlerine (Güneş ve Ay gibi) yönelik anlayışlarının Dünya'da bulunma varsayımına göre geliştirilen bakış açısı olan Dünya temelli bakış açısı ile oluşturulması (Plummer et al., 2014) olarak açıklamaktadır.

Bununla birlikte farklı kültürlerden çocuklarla yapılan pek çok çalışma çocukların astronomik olgulara ait bilimsel açıklamaları anlamada sorun yaşadığını ortaya koymaktadır (Kampeza, 2006; Küçüközer ve Bostan, 2010; Özsoy, 2012; Saçkes vd., 2016; Tao, Oliver, \& Venville, 2013; Valanides, Gritsi, Kampeza, \& Ravanis, 2000; Vosniadou, Skopeliti, Ikospentaki, 2004). Özellikle dünyanın işleyişine ilişkin çocuklar tarafından ortaya konan bazı naif/ alternatif/ birincil kavramlar gelişimsel psikoloji, bilişsel bilim ve eğitim bilimleri alanları araştırmacıları tarafından dikkatle incelenmektedir (Bartsch \& Wellman, 1989; Blown \& Bryce, 2006; Carey, 1985; Gopnik \& Astington, 1988; Saçkes vd., 2010; Vosniadou \& Brewer, 1992,1994).

Çocukların sahip oldukları astronomi kavramlarının özelliklerini ve bilgiyi edinme kaynaklarını inceleyen çalışmaların temel çatışma başlıkları; çocukların sahip oldukları alternatif kavramların kendi içinde tutarlı veya farklı bilgi parçacıklarının oluşturduğu bir yapıya sahip olduğu ve bu kavramların evrenselliği veya kültürel farklılıklara göre değişkenliğidir. Vosniadou (1994)' ya göre kavramsal değişim alanyazını iki varsayımı desteklemek üzerine bulgular sunmaktadır (Vosniadou, 1994'ten akt. Siegal, Butterworth, \& Newcombe, 2004). Bunlar: (1) yerleşik önvarsayımlar ve (2) kültürel aracılık varsayımlarıdır. Yerleşik önvarsayımlar hipotezi çocukların Dünya'nın şekli ve gece-gündüz oluşumu gibi kavramlara ilişkin sahip oldukları birincil 
zihinsel modellerin bu kavramlara dair inanç ve kavram yanılgılarına tutarlılık sağlayan naif çerçeve teorisine dayanmaktadır. Dünyanın şekli ve gece-gündüz kavramlarına ilişkin anlayışları şekillendiren yerleşik önvarsayımlar dünyanın düzlemsel olduğuna ilişkin (Düzlük koşulu) ve desteklenmeyen nesnenin düşeceğine ilişkin inançlardır (Destek koşulu) (Siegal vd., 2004). Vosniadou (1994) tarafından öne sürülen bu ön varsayımlar çocukların naif düşüncelerini etkileyerek bilimsel doğrulardan farklılaşmasını sağlamaktadır. Çocukların bu varsayımların kısıtlamalarıyla oluşturduğu kavramsal anlayışlar kendi içerisinde tutarlı, değişime dirençli birincil zihinsel modeller olarak tanımlanmaktadır (Vosniadou \& Brewer 1992,1994). Hannust ve Kikas (2007) ise tutarlı modelleri çocukların sahip olduğu bireysel doğruların birbiri ile sıkıca bağlantılı olduğu ve kavramsal bir bütünlük oluşturduğu bilgi yapıları olarak tanımlamaktadır. Bryce ve Blown (2013) ile Vosniadou ve Brewer $(1992,1994)$ 'in çalışmaları da bu tanımı destekleyici bulgular sunmaktadır. Parçacıkı bilgi teorisi ise farklı altyapıda teorilerle ilişkili olabilen ve bu nedenle birbiri ile tutarlı olmayan bağımsız ve ezberlenmiş doğruların bir araya gelmesini ifade etmektedir (Hannust \& Kikas, 2007). Alanyazında çocukların özellikle astronomi kavramları ile ilgili sahip oldukları bilgilerin parçacıklı bilgiler şeklinde olduğunu söyleyen çalışmalar bulunmaktadır (Hannust \& Kikas, 2007; Kampeza, 2006; Panagiotaki, Nobes, \& Potton, 2009; Straatemeier, van der Maas, Jansen, 2008). Çocukların astronomi ile ilgili sahip oldukları bilgilerin kaynağını sorgulayan çalışmalarda ise evrenselliğe karşı kültürel etkiler varsayımı üzerinde durulmaktadır. Vosniadou ve arkadaşları (2004) bilimsel bir kavramı içselleştirmenin doğrudan bir kültürel aktarımdan çok yapılandırılmanın gerçekleştiği bir süreç şeklinde olduğunu belirtirken; Siegal ve arkadaşları ise bazı bilgilerin sadece kültürel aktarım yoluyla kazanılabileceği öne sürmektedir (2004). Kikas'a göre astronomi teorileri çocukların gelişim rotasında radikal yeniden yapılanmalara maruz kalmaktadır ve ayrıca çocukların astronomi ile ilgili tanımları ve açıklamaları antik ve orta çağdakilerle benzerlik göstermektedir (1998).

Vosniadou ve Brewer (1992) çalışmalarında ilk olarak 1., 3. ve 5. sınıfa devam eden çocukların sahip olduğu dünyanın şekline ilişkin zihinsel modelleri incelemişlerdir. Araştırma sonuçları çocukların başlangıçta, dünyanın düz veya köşeli disk şeklinde olduğu ve alttan yer tarafından desteklendiği, üstten ise gökyüzü ve diğer gök cisimleri (güneş, ay) tarafından çevrelendiğine ilişkin zihinsel modelleri olduğunu göstermiş̧ir. Küre şeklindeki dünya ile ilgili bir öğretim etkisi görülmediğinden, bu modeller çocuğun günlük deneyimleri ile tutarlı görünmekte ve bu nedenle birincil modeller olarak isimlendirilmektedir. Büyük çocuklarda ise sıklıkla küresel dünya ve birincil modellerin görünüşlerinin birleşimi şeklinde sentetik olarak adlandırılan modeller saptanmıştır (Ek 1.). Vosniadou ve Brewer (1994) daha sonraki çalışmalarında ise 1., 3. ve 5. sınıf çocuklarının gündüz ve gece döngüsüne ilişkin kavramsal anlayışları incelemişler ve çocukların gece gündüz oluşumu olgusunu mantıksal olarak tutarlı bazı modeller kullanarak açıkladıklarını ortaya koymuşlardır (Ek 2.). Küçük çocuklarda gündelik deneyimlere dayanan birincil modeller daha sıklıkla görülürken, daha büyük çocuklarda daha karmaşık ve bilimsel modele dayalı olarak sentezlenmiş sentetik modeller görülmektedir. Çok az sayıda çocuk ise gece ve gündüz oluşumuna ilişkin bilimsel doğruları ve açıklamaları içeren tanımlamalar yapmışlardır. Vosniadou ve Brewer tarafından yapılan bu çalışmalar bu alana ilişkin çalışmalar arasında öncü olarak kabul edilmekte ve ortaya koydukları modeller pek çok araştırmacı tarafından kullanılmakta; farklı çalışma desenleri ve örneklem gruplarılya denenmekte ve güncellenmektedir.

Erken çocukluk dönemindeki öğrenme deneyimleri bilimsel bilgiler ve sorgulama becerilerine temel olmaları bakımından çok önemlidir (Eshach \& Fried, 2005; Patrick, Mantzicopoulos, \& Samarapungavan, 2009; Samarapungavan, Mantzicopoulos, \& Patrick, 2008; Trundle \& Saçkes, 2012). Çocuklar yaşamlarının ilk yıllarından itibaren, Dünya, gök cisimleri ile bunların özelliklerine ait kavramlar ve döngülere ilişkin (gece-gündüz, mevsimler) gözlemler, kültürel açıklamalar ve bilimsel doğrular aracılı̆ı̀la bilgi edinmektedirler. Çocukların bu bilgileri ilgili alanyazın kapsamında derinlemesine incelenmiş ve özetle değişime dirençli ve sonraki öğrenmeleri etkileme gücüne sahip olarak tanımlanmıştır (Saçkes, 2015; Trundle \& Saçkes, 2012). 
Çocuklar okula astronomik olgularla ilgili güncel bilimsel teorilerden farklı ve bilim eğitimi ile değişmesi gereken naif teoriler ile başlamaktadır. Erken yaşlarda Dünya'nın şekli ve GeceGündüz oluşumuna ilişkin kavramsal anlayışları incelemek, bu anlayışların çocukların ilerleyen dönemlerdeki öğrenmelerini etkileyebileceği düşünüldüğünde büyük önem taşımaktadır. 60-72 aylık çocukların Dünya'nın şekli ve gece-gündüz oluşumuna ilişkin zihinsel modellerini ortaya koymak amacıyla yapılan bu araştırmada Vosniadou ve Brewer (1992;1994) tarafından ortaya konulmuş olan Dünya ve gece-gündüz oluşumuna ilişkin zihinsel modeller kullanılmaktadır (Ek 1. ve 2.).

\section{YÖNTEM}

\section{Araştırma modeli:}

Karma yöntemde iç-içe model olarak tasarlanan bu çalışmada toplanan veriler birlikte ve nicel olarak analiz edilip yorumlanmıştır. İç içe karma modelin varsayımlarına dayanarak iki farklı türde veri seti birbirini destekler nitelikte ele alınmış (Creswell \& Plano Clark, 2007), çocukların dünyanın şekli ve gece-gündüz oluşumuna ilişkin kavramsal anlayışlarını bütüncül bir bakış açısıyla ortaya koymak amaçlanmışıı.

\section{Çalışma Grubu:}

Araştırmanın çalışma grubunu 2015-2016 eğitim öğretim yılında kuzeybatı Anadolu'da bulunan bir büyükşehrin Milli Eğitim Müdürlüğü'ne bağlı bir bağımsız anaokuluna devam eden, yaşları 60- 72 aylar arasında değişen 31 kı 25 erkek olmak üzere toplam 56 çocuk oluşturmuştur. Çalışma grubunu oluşturan çocukların oluşturduğu üç sınıf seçkisiz olarak belirlenmiştir.

\section{Veri Toplama Araçları:}

Bu araştırmada çocukların Dünya'nın şekli ve gece gündüz oluşumuna ilişkin zihinsel modellerini ortaya koyabilmek için "Dünya-2" testi ve "Dünya ve Gece-Gündüz Görüşme Protokolü" kullanılmaktadır. Ölçme araçları uygulamacı için özel bir eğitim veya ön koşul gerektirmemektedir. Araştırmada Straatemeier ve arkadaşları (2008) tarafından geliştirilen orijinal adı Earth-2 EArth Representation Test for CHildren) olan, Dünya-2 testi kullanılmıştır. Dünya-2 testi küçük çocuklarla da kullanılabilen yapılandırılmış, sözel olmayan ve seçim yönelimli (forced choice) bir kağıt-kalem testi olarak tanımlanmaktadır. Dünya-2 testi biri örnek soru olmak üzere 10 sorudan oluşmaktadır. Testte dünyanın şekline ilişkin 7 soru, gündüz ve gece oluşumuna ilişkin ise 2 soru bulunmaktadır. Testin soruları dünyanın şekli ve gece gündüz oluşumuna ilişkin alan yazında ortaya konulmuş kavramsal modellerin iki boyutlu temsilleri içerisinden uygun olanı seçmeye olanak vermektedir. Dünya-2 soruları çalışma grubunda bulunan çocuklara sözel olarak sorulmakta, çocukların cevapları göstermeleri ve/veya ifade etmeleri istenmekte ve bu cevaplar kaydedilmektedir. Dünya-2 testi, Vosniadou ve arkadaşları (2004) tarafından yapılan çalışmanın önerileri doğrultusunda seçim yönelimli sorulara modellerin resimleri eklenerek iç tutarlılı̆ı yüksek cevaplar elde etmek amacıyla tasarlanmıştır. Straatemeier ve arkadaşlarının (2008) testin iç tutarlıığına ilişkin analiz sonuçları, Cronbach Alpha değerini .79 olarak göstermektedir. Güçhan Özgül ve Saçkes (2015) tarafından yapılan uyarlama çalışması kapsamında Dünya-2 testinin Cronbach Alpha değeri .56, Rasch analizi güvenirlik katsayısı ise .58 olarak belirtilmektedir. Bu çalışma kapsamında yapılan analizlerde Dünya-2 testine ilişkin güvenirlik katsayısı .69 olarak bulunmuştur.

Araştırmada çocukların Dünya'nın şekli ve gece-gündüz kavramlarına ilişkin görüşlerini ortaya çıkarmak amacıyla geliştirilen görüşme protokolü kullanılmıştır (Saçkes ve Korkmaz, 2015). Bu form soruları sözel ifadelerle yanıtlama, model oluşturma ve araştırmacının oluşturduğu modeller üzerinden seçim yapma gibi üç bölümden oluşmaktadır. Forma başlamadan önce kısaca görüşme süreci anlatılmakta, görüşmeye konu olan kavramlardan söz 
edilmekte ve çocuklara katılma veya katılmama durumları sorulmaktadır. Çocukların verdikleri yanıtlar ses kaydı, uygulayıcı tarafından alınan görsel kayıtlar ve notlar olarak kaydedilmektedir.

Verilerin Analizi: Dünya-2 testi ve görüşme protokolü araştırmacılar tarafından Dünya'nın şekli ve gece-gündüz oluşumuna ilişkin alanyazında ortaya konulan zihinsel modeller çerçevesinde kodlanmaktadır (Ek 1. ve 2.). Dünya-2 testinde yer alan şekiller birincil, sentetik ve bilimsel zihinsel modelleri göstermektedir. Bu nedenle test soruları 0 (birincil), 1 (sentetik) ve 2 (bilimsel) şeklinde kodlanarak analiz edilmektedir. Görüşme protokolü de aynı şekilde alanyazında yer alan Dünya'nın şekli ve gece-gündüz oluşumuna ilişkin zihinsel modelleri ortaya çıkarmak amacıyla benzer şekilde kodlanmaktadır. Bu kodlama çocukların sahip oldukları zihinsel modellerin bilimsel olma/olmama durumunu, günlük gözlemlerden yararlanma veya kültürlenme etkisini temele alarak yapılmaktadır. Çocukların Dünya-2 testinde seçtikleri ve görüşme protokolünde tanımladıkları ve/ya oluşturdukları modeller aynı zamanda modele ilişkin alt kavramlar olarak da kodlanabilmektedir. Örneğin sentetik modele sahip olduğu tespit edilen çocuğun, sentetik modele ait düzleştirilmiş, boş küre veya çift dünya kavramlarından birisine de atanması mümkün olabilmektedir. Çocukların teste ve görüşme protokolüne verdikleri yanıtlar ve oluşturdukları modeller belirtilen şekilde kodlanarak nicel veriye dönüştürüldükten sonra istatistiksel analizlere tabi tutulabilmektedir.

\section{BULGULAR}

Çocukların Dünya'nın şekli ve gece-gündüz oluşumuna ilişkin kavramsal anlayışları Dünya-2 testi ve görüşme protokolünün ilgili bölümlerine verdikleri sözel cevaplar ve oluşturdukları oyun hamuru modelleri kapsamında incelenmiştir. Veri analizine ait bulgular tablolar şeklinde verilecek olup, bunun yanı sıra çocukların görüşme protokolüne göre verdikleri cevap ve tamamladıkları görevlerine ilişkin örnekler bu tablolarla birlikte sunulacaktır.

\section{Dünya'nın Şekli}

Çocukların Dünya'nın şekline ilişkin anlayışlarını gösteren bulgular Tablo 1.'de verilmektedir. Tablo 2. kapsamında sentetik modele sahip çocuklardan ikisinin görüşme protokolüne verdikleri yanıtlar ve tamamladıkları görevler görsel olarak sunulmaktadır.

Tablo 1.

Dünya'nın Şekline Iliş̧kin Kavramsal Modeller

\begin{tabular}{|c|c|c|c|c|c|}
\hline \multicolumn{3}{|c|}{$N: 56$} & \multicolumn{2}{|c|}{$\begin{array}{c}f \\
\text { (grupiçi \%) }\end{array}$} & \multirow[t]{2}{*}{$\begin{array}{c}\text { Toplam } \\
f(\%)\end{array}$} \\
\hline \multicolumn{3}{|c|}{ Cinsiyet } & K & $\mathrm{E}$ & \\
\hline \multirow{8}{*}{$\begin{array}{l}\text { Dünyanın } \\
\text { Şekline İlişkin } \\
\text { Kavramsal } \\
\text { Anlayışlar }\end{array}$} & \multirow{2}{*}{ Birincil } & Disk & \multirow[b]{2}{*}{ - } & \multirow[b]{2}{*}{ - } & \multirow[t]{2}{*}{ - } \\
\hline & & Köşeli disk & & & \\
\hline & \multirow{5}{*}{ Sentetik } & Düzleştirilmiş küre & $26(46,4)$ & $25(44,6)$ & $\begin{array}{c}51 \\
(91,0)\end{array}$ \\
\hline & & Boş küre & $1(1,78)$ & - & $1(1,78)$ \\
\hline & & Çift dünya & $3(5,34)$ & - & $3(5,34)$ \\
\hline & & Simit & - & $1(1,78)$ & $1(1,78)$ \\
\hline & & Toplam & $30(53,3)$ & $26(46,7)$ & $56(100)$ \\
\hline & & Bilimsel & - & - & - \\
\hline
\end{tabular}

Görüşmeler kapsamında tümü sentetik modele sahip olduğu görülen çocukların \%91'i $(f=51)$ düzleştirilmiş dünya modeline $\% 5,34^{\prime}$ ü $(f=3)$ çift dünya modeline, $\% 1,78(f=1)$ boş küre ve \%1.78 $(f=1)$ simit dünya modeline göre alt gruplara ayrılmaktadırlar. Bulgular, çift dünya ve 
boş küre modelinin kız öğrenciler, simit modelinin ise bir (1) erkek öğrenci tarafından benimsendiğini göstermektedir.

Tablo 2.

Dünya'nın Şekline Iliş̧kin Kavramsal Modeller (Görüşme Dökümü SÇ-1, SÇ-2)

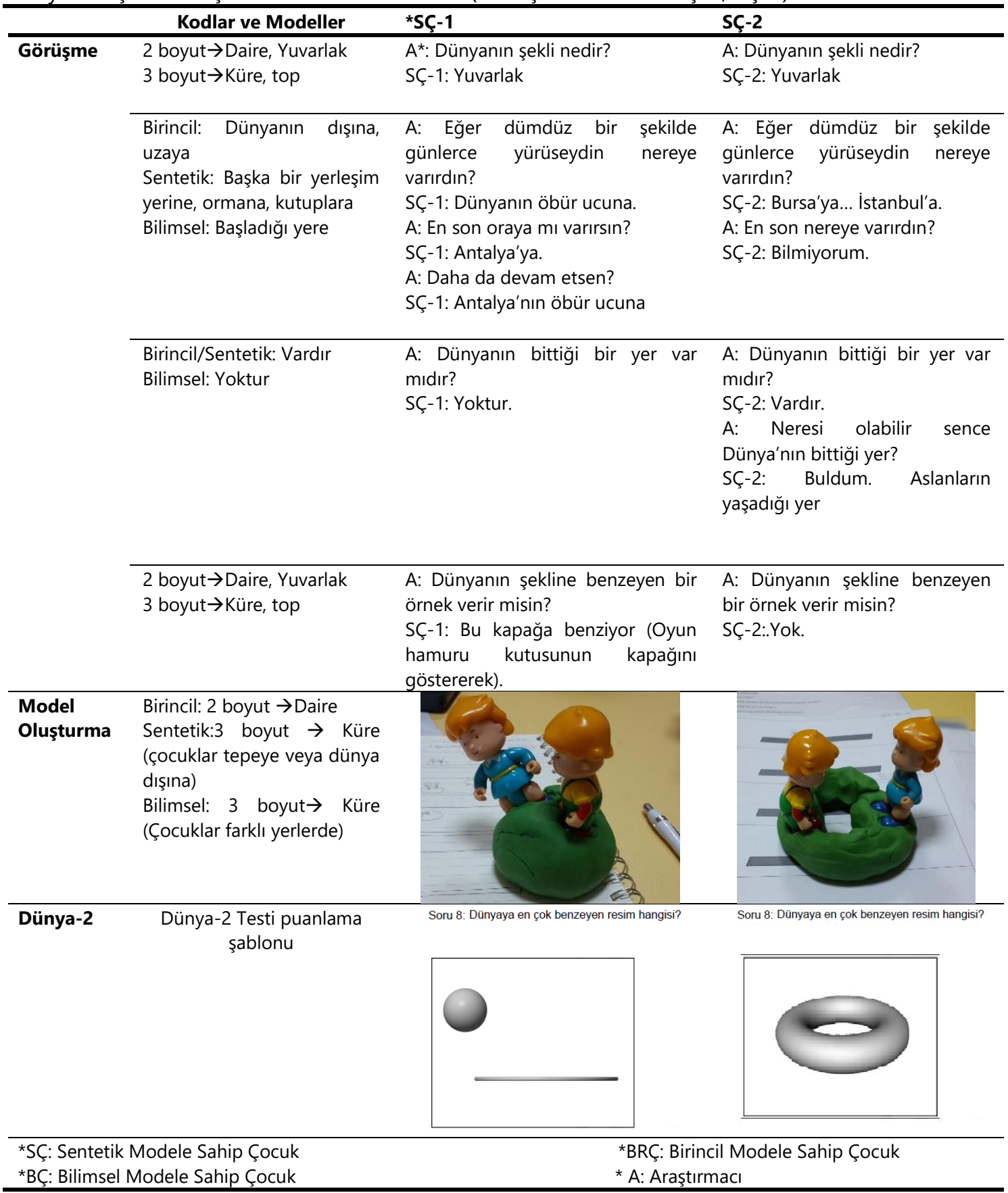

Çocuklar bazı sorularda ve/ya görüşme araçlarında/görevlerde bilimsel doğruluğu olan cevaplar vermiş olsalar da diğer sorularda verdikleri cevaplar, alternatif kavrayışlara sahip olduklarına işaret etmiştir (bknz. Tablo 2). Bu verilerden yola çıkılarak çocukların tamamının Dünya'nın şekline ilişkin olarak sentetik modeli benimsedikleri görülmüştür. 


\section{Gece-Gündüz Oluşumu}

Çocukların Gece-Gündüz kavramlarına ilişkin zihinsel modelleri Dünya-2 testi ve görüşme protokolünden aldıkları puanlara göre incelenmiştir. Bu incelemeye ait bulgular Tablo 3. ve 4.'te sunulmaktadır. Tablo 5. kapsamında Gece-Gündüz oluşumuna ilişkin sentetik zihinsel modele sahip olarak bulunan SÇ-3'in görüşme protokolü dökümü incelenebilir.

Tablo 3.

Gece-Gündüz Oluşumuna İlişkin Kavramsal Modeller

\begin{tabular}{|c|c|c|c|}
\hline \multicolumn{2}{|c|}{$\mathrm{N}=56$} & \multicolumn{2}{|c|}{ Deney $f$ (grupiçi \%) } \\
\hline \multicolumn{2}{|c|}{ Cinsiyet } & $\mathrm{K}$ & $E$ \\
\hline \multirow{3}{*}{$\begin{array}{l}\text { Gece-Gündüz } \\
\text { Kavramlarına İlişkin } \\
\text { Anlayışlar }\end{array}$} & Birincil & - & - \\
\hline & Sentetik & $30(53,57)$ & $26(46,43)$ \\
\hline & Bilimsel & - & - \\
\hline
\end{tabular}

Tablo 3. incelendiğinde çalışma grubundaki çocukların tümünün Gece-Gündüz oluşumuna ilişkin sentetik kavramsal anlayışlara sahip olduklarını görülmektedir.

Tablo 4.

Gece-Gündüz Oluşumuna İlişkin Kavramsal Alt Modeller

\begin{tabular}{|c|c|c|c|c|c|c|c|c|}
\hline \multicolumn{3}{|r|}{$\mathrm{N}=56$} & \multicolumn{2}{|c|}{ GÖRÜŞME } & \multicolumn{2}{|c|}{ MODEL OLUŞTURMA } & \multicolumn{2}{|c|}{ DÜNYA-2 } \\
\hline & & & $\mathbf{K}$ & $\mathbf{E}$ & $\mathbf{K}$ & $\mathbf{E}$ & $\mathbf{K}$ & $\mathbf{E}$ \\
\hline \multirow{15}{*}{ 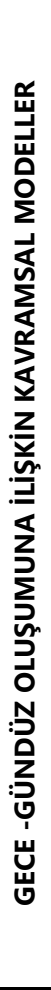 } & \multirow{6}{*}{ 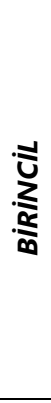 } & Güneşin uzaklaşması & $2 \mathrm{~K}$ & $1 \mathrm{E}$ & $5 K$ & $1 \mathrm{E}$ & $3 \mathrm{~K}$ & $2 \mathrm{E}$ \\
\hline & & Güneşin gizlenmesi & $8 \mathrm{~K}$ & $2 \mathrm{E}$ & $7 \mathrm{~K}$ & $5 \mathrm{E}$ & $9 \mathrm{~K}$ & $8 \mathrm{E}$ \\
\hline & & Güneşin aşağı gitmesi & $5 K$ & $5 \mathrm{E}$ & $8 \mathrm{~K}$ & $6 \mathrm{E}$ & $10 \mathrm{~K}$ & $9 \mathrm{E}$ \\
\hline & & Güneşin aynı yerde olması & $3 K$ & $4 \mathrm{E}$ & $2 K$ & $5 E$ & & \\
\hline & & Allah & $2 \mathrm{~K}$ & $4 \mathrm{E}$ & & & & \\
\hline & & Ayla ilgili & $1 \mathrm{~K}$ & & & & & \\
\hline & \multirow{6}{*}{$\underset{\text { 岕 }}{\stackrel{5}{*}}$} & Güneşin dönüşü & $2 \mathrm{~K}$ & $4 \mathrm{E}$ & $5 K$ & $2 \mathrm{E}$ & $5 K$ & $3 \mathrm{E}$ \\
\hline & & Dönüş+Gizlenme & $1 \mathrm{~K}$ & & & & & \\
\hline & & Dönüş+Uzaklaşma & & $1 \mathrm{E}$ & $1 \mathrm{E}$ & & & \\
\hline & & Dönüş+Aşağı Gitme & & $2 \mathrm{E}$ & $2 \mathrm{~K}$ & $1 \mathrm{E}$ & & \\
\hline & & Dönüş+Aynı yerde olma & & & & & & \\
\hline & & Güneşin etrafında dönüş & & & & & & \\
\hline & 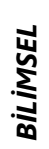 & $\begin{array}{c}\text { Dünyanın dönmesi, } \\
\text { güneşin diğer tarafı } \\
\text { aydınlatması }\end{array}$ & $4 \mathrm{~K}$ & $1 \mathrm{E}$ & $2 \mathrm{~K}$ & $2 \mathrm{E}$ & $4 \mathrm{~K}$ & $3 E$ \\
\hline & & Diğer* & $4 \mathrm{~K}$ & & & $2 \mathrm{E}$ & & \\
\hline & & Toplam & 32 & 24 & 32 & 24 & 31 & 25 \\
\hline
\end{tabular}

Not: $K=K ı z, E=$ Erkek

*: "Bilmiyorum" cevabı fazlaysa, cevaplar anlaşılamıyorsa veya cevap yoksa bu kategoriye alınmıştır.

Bulgular, alt modeller bazında bilgi veren Tablo 4.'e göre ayrıntılı olarak incelendiğinde, çocukların "Dünya'nın kendi etrafında dönerek Güneş'in dünyanın farklı taraflarını aydınlatması"nı ifade eden bilimsel modelden farklı olarak gece gündüz oluşumunu Güneş'in hareketi, Dünya'nın dönüşü ve uzaklaşma gibi kavramsal modeller çerçevesinde açıkladıkları görülmektedir. 
Tablo 4. incelenirken çocukların tümünün görüşme, model oluşturma, model tanımlama ve Dünya-2 testi basamaklarının en az birinde sentetik veya birincil kavramları gösteren yanıtlar verdiği bu nedenle kavramsal anlayış olarak sentetik olarak rapor edildiği göz önünde bulundurulmalıdır. Bu bilgi ışığında, çalışma grubunu oluşturan çocuklarda birincil modele rastlanmamıştır. Görüşme protokolünün en az bir bölümünde kültürlenme olarak adlandırdığımız çevre, eğitim veya bilimsel doğruluğu olan bilgilerle karşılaşılan durum ve/ya ortamlara maruz kalmanın etkisiyle oluşturulan sentetik modelleri içeren kavramsal anlayışlar ortaya çıktığı için tüm çocuklar sentetik modele sahip olarak ilgili gruba atanmıştır.

\section{Tablo 5.}

Gece-Gündüz Oluşumuna Illişkin Kavramsal Alt Modeller (SÇ-3 Görüşme Dökümü)

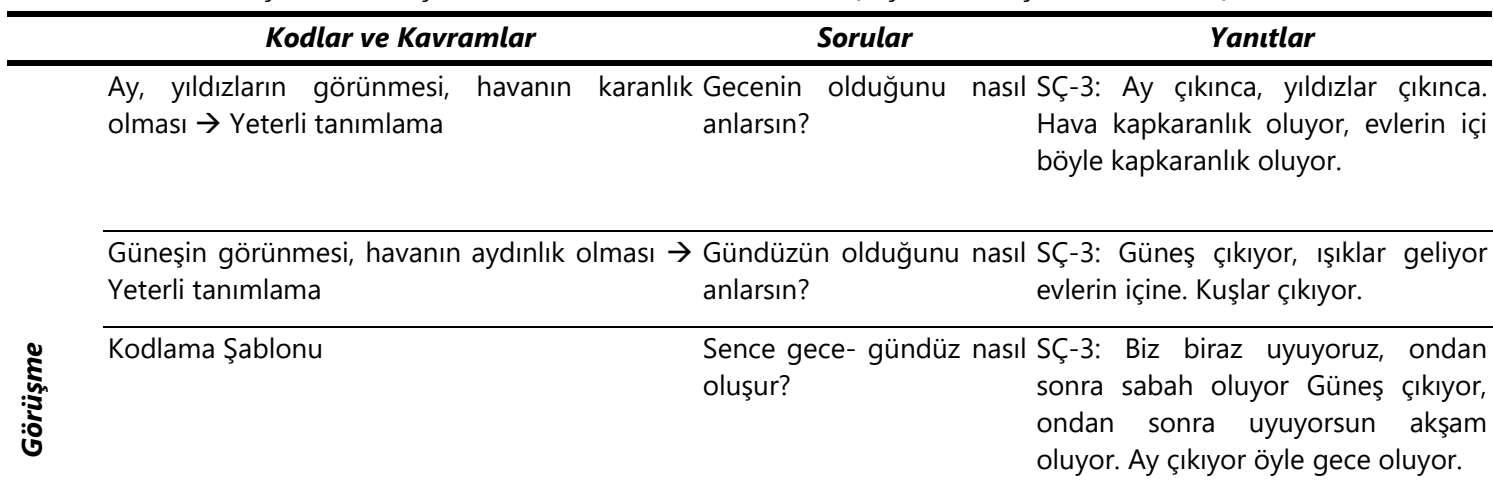

Geceleri Dünya'nın diğer tarafında $\rightarrow$ Yeterli Sence neden gökyüzünde Çünkü bulutların arkasına gidiyor. (bilimsel) tanımlama güneş bazı zamanlarda

Bulutların arkasında, az parlak/ çok parlak, görünüyorken bazı Bulutların arkasında, az parlak/ çok parlak, zamanlarda görünmüyor? tanımlama

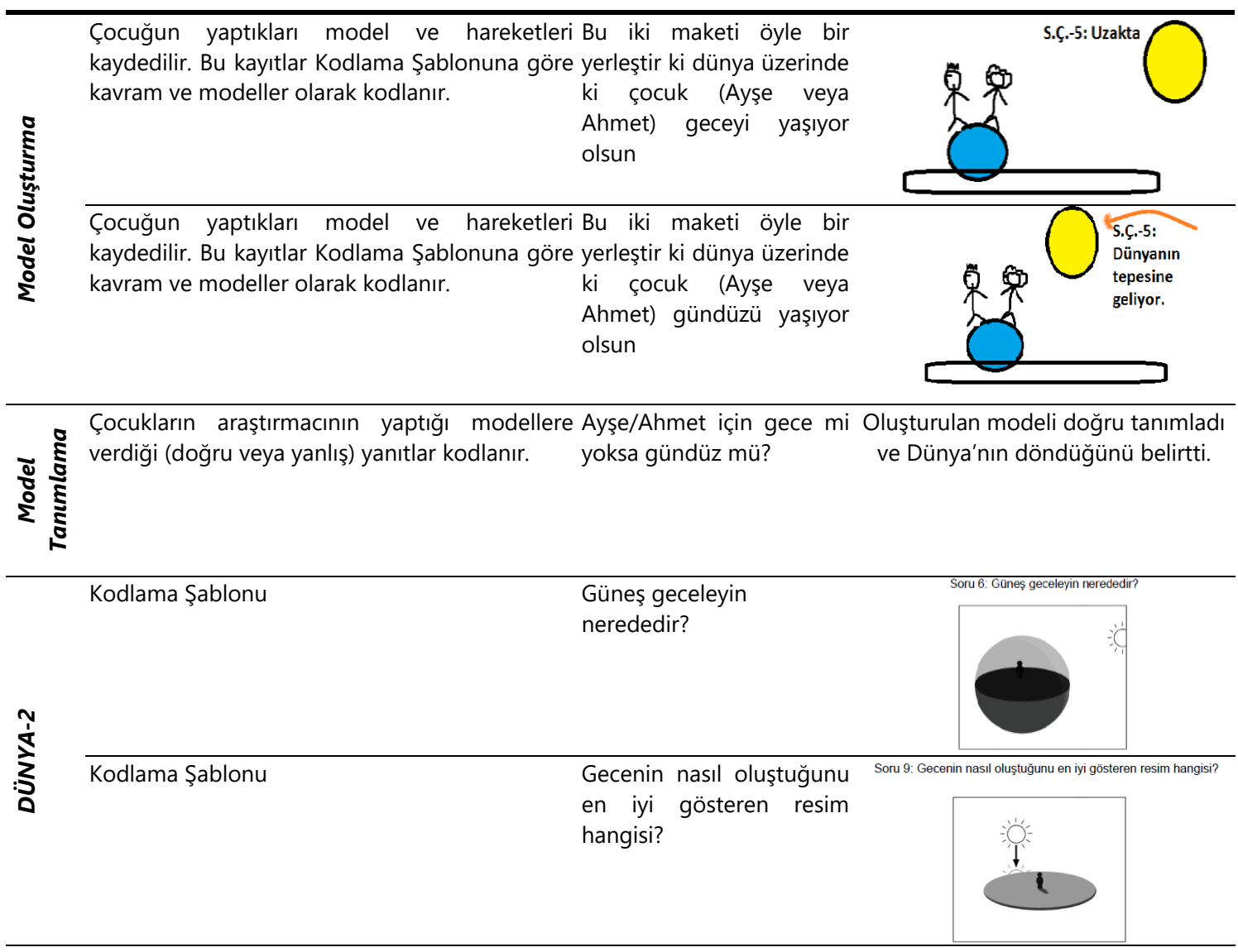

*SÇ: Sentetik Modele Sahip Çocuk *BRÇ: Birincil Modele Sahip Çocuk * *BÇ: Bilimsel Modele Sahip Çocuk *A: Araştırmacı 
Tablo 5. incelendiğinde SÇ-3 kodlu öğrencinin günlük gözlemlerinden büyük ölçüde yararlandığı ve bu doğrultuda bazı sorularda birincil modele uygun cevaplar verdiği görülmektedir. Bunun yanında model tanımlama ve gece ile gündüzü betimleme gibi sorularda doğru cevaplar verip Dünya'nın dönüşüyle ilgili bilimsel doğruluğu olan bilgiye sahip olduğu da dökümde yer almaktadır.

\section{SONUÇ, TARTIŞMA VE ÖNERILER}

\section{Dünya'nın şekli}

Çocuklar günlük gözlem ve deneyimleri ile bilimsel öğrenmelerini sentezleyerek bilimsel olandan belirli noktalarda farklılaşan alternatif (sentetik) kavramlar oluşturmaktadırlar. Bu araştırma kapsamında çalışma grubundaki çocukların tümünün Dünya'nın şekliyle ilgili sentetik modelde kavramsal anlayışa sahip oldukları bulunmuştur. Bu bulgular Özsoy (2012) tarafından yapılan ve çocukların \%60'ının bilimsel modelden farklı alternatif modellere sahip olduğunu gösteren çalışmanın bulguları ile uyum göstermektedir.

Simit dünya modeline bu çalışmada da rastlanması Türkiye'de 6 yaş çocuklarının Dünya'nın şekline ilişkin kavramsal anlayışlarını inceleyen Saçkes ve Korkmaz'ın (2015) bulgularıyla örtüşmektedir. Her iki çalışmada da Amerikan ve Avrupalı çocuklarda pek rastlanmayan simit dünya modeli ortaya çıkmıştır. Yunanistan ve Hindistan gibi ülkelerde yaşayan çocuklarda da simit modelinin var olduğunu gösteren farklı çalışmalar bulunmaktadır (Samarapungavan, Vosniadou, \& Brewer, 1996; Vosniadou vd., 2004).

Bu çalışmada düzleştirilmiş dünya modeline çocukların büyük bir çoğunluğunda rastlanması Vosniadou tarafından ortaya konan dünyanın düzlemsel olduğuna ilişkin (Düzlük koşulu) ve desteklenmeyen nesnenin düşeceğine ilişsin (Destek koşulu) inançlarının kavramsal anlayışları şekillendirmesi varsayımını doğrular niteliktedir (Tao vd., 2013; Vosniadou vd., 2004).

1976 yılında 7-8 yaş çocuklarla yapılan çalışmada çocukların Dünya'ya ilişkin anlayışlarının bilimselden farklı olarak yerçekimi ve atmosfer ile ilgili bilgi ve gözlemlerle birlikte sentezlenerek bazı sentetik anlayışlara dönüştüğü bulunmuştur (Nussbaum \& Novak, 1976). Panagiotaki, Nobes ve Banerjee (2006) tarafından yapılan çalışmada farklı görüşme yöntemleri kullanılarak 6 yaş çocuklarıyla görüşülmüştür ve birincil modellere rastlanmamıştır. Araştırmacılar bu durumun yöntemsel bir soruna bağlı olduğunu belirtseler de bu çalışmanın çok boyutlu görüşmelere imkan veren yöntemine rağmen birincil modellerin çıkmaması Panagiotaki ve arkadaşlarının (2006) yorumlarıyla çelişmektedir. Günümüz Dünya'sında çocukların bilimsel bilgilerle çok erken yaşlarda tanışması ve birincil bilgileri belki de hiç edinmeden sentetik ve bilimsel anlayışlar kazanması (Panagiotaki vd., 2009) daha olası bir açıklama gibi görünmektedir.

\section{Gece-Gündüz Oluşumu}

Sözel cevaplama (görüşme), model oluşturma/seçme ve test cevaplama görevlerini içeren çok boyutlu bir protokol kullanılarak çocukların Dünya'nın şekli ve gece-gündüz oluşumuna ilişkin kavramsal anlayışlarını ortaya koymayı amaçlayan bu araştırmanın bulguları çalışma grubundaki çocukların gece-gündüz oluşumu ile ilgili sentetik modelde kavramsal anlayışa sahip olduklarını göstermektedir. Çok boyutlu görüşme protokolünün farklı boyutlarına verdikleri yanıtlar ve tamamladıkları model oluşturma ve tanımlama görevleri incelendiğinde çocukların büyük çoğunluğunun Gece-Gündüz oluşumunu Güneş' in hareketlerine bağlı bir olgu şeklinde algıladıkları görülmektedir. Gece-Gündüz kavramlarını Ay ve Allah ile ilişkilendiren çocuklara da rastlanmıştır. Görüşme protokolünün bazı alt boyutlarında Gece-Gündüz ilişkin kavramları bilimsel doğrular çerçevesinde yanıtlayan çocuklar da bulunmaktadır. Vosniadou ve Brewer (1994) tarafından yapılan çalışmada ortaya çıkan modellerden pek çoğuna bu çalışmada da rastlanmıştır (Tablo 4.). Vosniadou ve Brewer (1994) tarafından öne sürülen yaş faktörü bu 
çalışma kapsamında incelenmemiştir ve erken yaşlarda birincil modeller görülürken büyük yaşlarda sentetik ve bilimsel modellere rastlanmaktadır varsayımı bu çalışma için geçerli değildir.

Farklı ölçme araçlarından toplanan veriler birlikte değerlendirildiğinde çocukların bilimsel ve kültürel bilgilerle sentezlediği sentetik modellerin varlığından söz etmek mümkündür. Güneş'in Ay'ın veya bulutların arkasına gizlenmesi ve aşağı doğru gitmesi (batması) görüşme protokolünün tüm basamaklarında en çok ortaya çıkan kavramlar olmuştur. Çocukların günlük gözlemlerine dayalı gizlenme kavramı ve Türkçe dilinde yaygın olarak kullanılan Güneş'in batması ve doğması ile ilişkili olabileceği düşünülen aşağı ve yukarı hareket kavramı çocukların zihinsel yapılarında dikkate değer şekilde göze çarpmaktadır. Küçüközer ve Bostan (2010) tarafından yapılan çalışmanın bulguları da çocukların büyük kısmının $(\% 57,7)$ bilimsel doğrularla çelişen yanıtlar verdiklerini ve bu yanıtların özellikle güneşin farklı hareketleriyle ilişkili olduğunu göstermektedir. Saçkes, Trundle ve Smith' in erken çocuklukta bilimsel kavramların gelişimini ele aldıkları alanyazın incelemelerinde küçük çocukların günlük deneyimlerine dayandırarak gece gündüz oluşumunu Güneş'in hareketine atfettikleri belirtilmiştir (2015). Bu çalışmanın bulguları çalışma grubundan 6 çocuğun, Gece-Gündüz oluşumunu Allah'a atfettiklerini göstermektedir. Benzer şekilde, doğa olaylarının oluşumunu yaratıcıya, doğaüstü güçlere veya batıl inançlara bağlayan çocukların varlığı başka çalışmalarda da göze çarpmaktadır (Kampeza, 2006; Küçüközer ve Bostan, 2010; Saçkes vd., 2010; Valanides vd., 2000).

$\mathrm{Bu}$ araştırmanın sonucunda çalışma grubundaki 60-72 aylık çocukların çok boyutlu görüşme protokolünün farklı boyutlarına verdikleri yanıtlar ve tamamladıkları model oluşturma ve tanımlama görevleri incelendiğinde, çocukların Dünya'nın şekli ve gece-gündüz oluşumuna ilişkin gündelik gözlemleri ve bilimsel bilgileri sentezleyerek oluşturdukları alternatif kavramlara sahip oldukları bulunmuştur. Bu bilgi ışığında, okul öncesi eğitim dönemindeki çocukların sahip oldukları alternatif/sentetik yapıların bilimsel doğruluğu olan bilgilerle yer değiştirebilmesi için uygun öğretim müdahaleleri ve destekleri ile buluşturulması gerekmektedir. Alanyazında genişçe kabul gören alternatif kavramların değişime dirençli olduğu varsayımı, araştırmacılara ve eğitimcilere önemli sorumluluklar yüklemektedir: 1) Çocukların sahip oldukları kavramsal modelleri ortaya çıkarmak, 2) Var olan alternatif kavramsal yapıların bilimsel doğrulara evrilmesini sağlayacak öğretim müdahaleleri tasarlamak ve uygulamak.

Fen etkinliklerinin planlanması sürecinde okul öncesi dönem çocuklarının gelişimsel özelliklerinden ve ihtiyaçlarından yola çıkarak oyun, hareket ve etkileşim temelli olarak ve çocukların sorularını araştırma ve bilimsel süreç basamaklarını takip etme fırsatı veren araştırma/sorgulama temelli öğrenme döngülerini kullanarak tasarlanması önemli farklılıklar ortaya koyabileceğini destekleyen alanyazın incelemeleri (Akman, \& Güçhan Özgül, 2015) ve araştırmalar (Alabay, 2013; Bulunuz, 2013; Samarapungavan vd., 2008; Samarapungavan, Patrick, \& Mantzicopoulos, 2011) bulunmaktadır. Çalışma grubundaki çocukların tümünün ele alınan astronomi kavram ve olgularıly ilgili sentetik kavramsal anlayışa sahip olduğunu gösteren bu ve benzer çalışmaların bulguları ışı̆ıında okul öncesi dönem fen eğitimi çalışmalarının, bilimsel kavram ve olguları kazandırmaya ve/ya sahip olunan alternatif/sentetik kavramları bilimsel doğrularla değiştirmeye yönelik planlanması önerilmektedir.

\section{KAYNAKÇA}

Akman, B., \& Güçhan Özgül, S. (2015). Role of Play in Teaching Science in the Early Childhood Years. In Research in Early Childhood Science Education, 237-258. Springer Publishing

Akman, B., Üstün, E., \& Güler, T. (2003). 6 yaş çocuklarinin bilim süreçlerini kullanma yetenekleri. Hacettepe Üniversitesi Eğitim Fakültesi Dergisi, 24, 11-14.

Alabay, E. (2013). Scıencestart! $!^{T m}$ destekli fen eğitim programının 60-72 aylık çocukların bilimsel süreç becerilerine ve bilimsel tutuma güvenme ve yönelime etkisi. Yayımlanmamış Doktora Tezi, Selçuk Ünivesitesi Eğitim Bilimleri Enstitüsü, Konya. 
Ampartzaki, M., \& Kalogiannakis, M. (2016). Astronomy in Early Childhood Education: A Concept-Based Approach. Early Childhood Education Journal, 44(2), 169-179. http://doi.org/10.1007/s10643-015-0706-5

Bartsch, K., \& Wellman, H. (1989). Young Children's Attribution of Action to Beliefs and Desires, Child Development, 60, 946-964.

Blown, E. J., \& Bryce, T. G. K. (2006). Knowledge Restructuring in the Development of Children 's Cosmologies Knowledge Restructuring in the Development of Children's. International Journal of Science Education, 28(12), 1411-1462. http://doi.org/10.1080/09500690600718062

Bryce, T. G. K., \& Blown, E. J. (2013). Children's Concepts of the Shape and Size of the Earth, Sun and Moon. International Journal of Science Education, 35(3), 388-446. http://doi.org/10.1080/09500693.2012.750432

Bulunuz, M. (2013). Teaching science through play in kindergarten: does integrated play and science instruction build understanding? European Early Childhood Education Research Journal, 21(2), 226-249. http://doi.org/10.1080/1350293X.2013.789195

Carey, S. (1985). Conceptual Change in Childhood, Massachusetts: MIT Press.

Creswell, J. W., \& Plano Clark, V. L. (2007). Designing and conducting mixed methods research.Thousand Oaks, CA: Sage.

Eshach, H., \& Fried, M. N. (2005). Should science be taught in early childhood? Journal of Science Education and Technology, 14(3), 315-336. http://doi.org/10.1007/s10956-005-7198-9

French, L. (2004). Science as the center of a coherent, integrated early childhood curriculum. Early Childhood Research Quarterly, 19(1), 138-149. http://doi.org/10.1016/j.ecresq.2004.01.004

Gelman, R., \& Brenneman, K. (2004). Science learning pathways for young children. Early Childhood Research Quarterly, 19(1), 150-158. http://doi.org/10.1016/j.ecresq.2004.01.009

Gelman, S. A. (2005). Early conceptual development. In K. McCartney \& D. Phillips (Eds.), Blackwell Handbook of Early Childhood Development. Singapore: Blackwell Publishing.

Gopnik, A., \& Astington, J. W. (1988). Children's Understanding of Representational Change and Its Relation to the Understanding of False Belief and the Appearance-Reality Distinction. Child Development, 59(1), $26-37$.

Güçhan Özgül, S., \& Saçkes, M. (2015). Adaptation of EARTH-2 Scale for Turkish Kindergartners. EECERA (Özet bildiri) (Yayın No:2154415) Barcelona, İspanya.

Hannust, T., \& Kikas, E. (2007). Children's knowledge of astronomy and its change in the course of learning. Early Childhood Research Quarterly, 22(1), 89-104. http://doi.org/10.1016/j.ecresq.2006.11.001

Hayes, B. K., Goodhew, A., Heit, E., \& Gillan, J. (2003). The role of diverse instruction in conceptual change. Journal of Experimental Child Psychology, 86, 253-276. http://doi.org/10.1016/j.jecp.2003.09.002

Kallery, M. (2011). Astronomical Concepts and Events Awareness for Young Children. International Journal of Science Education, (October 2013), 341-369. http://doi.org/10.1080/09500690903469082

Kampeza, M. (2006). Preschool children's ideas about the Earth as a cosmic body and the day / night cycle. Journal of Science Education, 7(2), 119-122.

Kikas, E. (1998). The impact of teaching on students' definitions and explanations of astronomical phenomena. Learning and Instruction, 8(5), 439-454. http://doi.org/10.1016/S0959-4752(98)00004-8

Küçüközer, H., \& Bostan, A. (2010). Ideas of kındergarten students on the day-nıght cycles, the seasons and the moon phases. Eğitimde Kuram ve Uygulama, 6(2), 267-280.

Mantzicopoulos, P., Patrick, H., \& Samarapungavan, A. (2008). Young children's motivational beliefs about learning science. Early Childhood Research Quarterly, 23(3), 378-394. http://doi.org/10.1016/j.ecresq.2008.04.001

N.R.C. (1996). National Science Education Standards. Science Education. http://doi.org/0-309-54985-X

Nussbaum, J., \& Novak, J. D. (1976). An Assessment of Children's Concepts of the Earth Utilizing Structured Interviews, Science Education, 60(4), 535-550.

Özsoy, S. (2012). Is the Earth Flat or Round? Primary School Children's Understandings of the Planet Earth:The Case of Turkish Children. International Electronic Journal of Elementary Education, 4(2), 407-415.

Panagiotaki, G., Nobes, G., \& Banerjee, R. (2006). Children ' s representations of the earth: A methodological comparison. British Journal of Developmental Psychology, 24, 353-372. http://doi.org/10.1348/026151005X39116

Panagiotaki, G., Nobes, G., \& Potton, A. (2009). Journal of Experimental Child Mental models and other misconceptions in children 's understanding of the earth. Journal of Experimental Child Psychology, 104(1), 52-67. http://doi.org/10.1016/j.jecp.2008.10.003 
Patrick, H., Mantzicopoulos, P., \& Samarapungavan, A. (2009). Motivation for learning science in kindergarten: Is there a gender gap and does integrated inquiry and literacy instruction make a difference. Journal of Research in Science Teaching, 46(2), 166-191. http://doi.org/10.1002/tea.20276

Plummer, J. D., Kocareli, A., Slagle, C., Diane, J., Kocareli, A., \& Slagle, C. (2014). Learning to Explain Astronomy Across Moving Frames of Reference: Exploring the role of classroom and planetarium-based instructional contexts, 693(October 2016). http://doi.org/10.1080/09500693.2013.843211

Saçkes, M. (2015). Kindergartners' Mental Models of the Day and Night Cycle: Implications for Instructional Practices in Early Childhood Classrooms, Educational Sciences: Theory and Practice, 15(4), 997-1006. http://doi.org/10.12738/estp.2015.4.2741

Saçkes, M., \& Korkmaz, H. İ. (2015). Anaokulu Çocuklarının Dünyanın Şekline İlişkin Zihinsel Modelleri, ilköğretim Online 14(2), 734-743.

Saçkes, M., Flevares, L. M., \& Trundle, K. C. (2010). Four- to six-year-old children's conceptions of the mechanism of rainfall. Early Childhood Research Quarterly, 25(4), 536-546. http://doi.org/10.1016/j.ecresq.2010.01.001

Saçkes, M., Smith, M. M., \& Trundle, K. C. (2016). US and Turkish preschoolers ' observational knowledge of astronomy. International Journal of Science Education, 38(1), 116-129. http://doi.org/10.1080/09500693.2015.1132858

Saçkes, M., Trundle, K. C., \& Smith, M. M. (2015). Development of Scientific Concepts During Childhood. In International Encyclopedia of Social \& Behavioral Sciences (2nd edition). Elsevier.

Saçkes, M., Trundle, K. C., Bell, R. L., \& O'Connell, A. a. (2011). The influence of early science experience in kindergarten on children's immediate and later science achievement: Evidence from the Early Childhood Longitudinal Study. Journal of Research in Science Teaching, 48(2), 217-235. http://doi.org/10.1002/tea.20395

Samarapungavan, A. L. A., Mantzicopoulos, P., \& Patrick, H. (2008). Learning Science Through Inquiry in Kindergarten. Science Education, 92(March 2007), 868-908. http://doi.org/10.1002/sce.20275

Samarapungavan, A., Patrick, H., \& Mantzicopoulos, P. (2011). What Kindergarten Students Learn in Inquiry-Based Science Classrooms. Cognition and Instruction, 29(4), 416-470. http://doi.org/10.1080/07370008.2011.608027

Samarapungavan, A., Vosniadou, S., \& Brewer, W. F. (1996). Mental models of the earth, sun, and moon: Indian children's cosmologies. Cognitive Development, 11(4), 491-521. http://doi.org/10.1016/S0885-2014(96)90015-5

Siegal, M., Butterworth, G., \& Newcombe, P. A. (2004). Culture and children's cosmology. Developmental Science, 7(3), 308-324. http://doi.org/10.1111/j.1467-7687.2004.00350.x

Sneider, C. I., \& Ohadi, M. M. (1998). Unraveling Students ' Misconceptions about the Earth 's Shape and Gravity. Scandinavian Journal of Educational Research, 82(2), 265-284.

Straatemeier, M., van der Maas, H. L. J., \& Jansen, B. R. J. (2008). Children's knowledge of the earth: a new methodological and statistical approach. Journal of Experimental Child Psychology, 100(4), 276-96. http://doi.org/10.1016/i.jecp.2008.03.004

Tao, Y., Oliver, M., \& Venville, G. (2013). Chinese and Australian children's understandings of the Earth: A cross cultural study of conceptual development. Cultural Studies of Science Education, 8(2), 253-283. http://doi.org/10.1007/s11422-012-9415-1

Trundle, K. C., \& Saçkes, M. (2012). Science and early education. Handbook of Early Childhood Education, 240-258.

Tu, T. (2006). Preschool Science Environment: What Is Available in a Preschool Classroom? Early Childhood Education Journal, 33(4), 245-251. http://doi.org/10.1007/s10643-005-0049-8

Valanides, N., Gritsi, F., Kampeza, M., \& Ravanis, K. (2000). Changing Pre-school Children's Conceptions of the Day/Night Cycle. International Journal of Early Years Education, 8(1), 27-39. http://doi.org/10.1080/096697600111725

Vosniadou, S., \& Brewer, W. F. (1992). Mental models of the earth: A study of conceptual change in childhood. Cognitive Psychology, 24(4), 535-585. http://doi.org/10.1016/0010-0285(92)90018-W

Vosniadou, S., \& Brewer, W. F. (1994). Mental models of the day/night cycle. Cognitive Science, 18, 123-183. http://doi.org/10.1016/0364-0213(94)90022-1

Vosniadou, S., Skopeliti, I., \& Ikospentaki, K. (2004). Modes of knowing and ways of reasoning in elementary astronomy. Cognitive Development, 19(2), 203-222. http://doi.org/10.1016/j.cogdev.2003.12.002

Wellman, H. M., \& Gelman, S. A. (1998). Knowledge acquisition in foundational domains. Handbook of Child Psychology: Volume 2: Cognition, Perception, and Language. 


\title{
Children's Mental Models about the Shape of the Earth and Day-Night Concepts*
}

\author{
Res. Assist. Dr. Sinem Güçhan Özgül \\ Balıkesir University-Turkey \\ sinem@balikesir.edu.tr
}

Prof.Dr. Berrin Akman

Hacettepe University-Turkey

bakman@hacettepe.edu.tr

\author{
Assoc.Prof.Dr. Mesut Saçkes \\ Balıkesir University-Turkey \\ msackes@gmail.com
}

\begin{abstract}
This study aimed to investigate 60-72 months old children's mental models about the shape of the Earth and day-night concepts. The sample of the study consisted of 56 children (31 girls, 25 boys) aged between 60-72 months attending the kindergarten in a city center located in the Northwestern part of Turkey.

Within the aim of this study, the data obtained from qualitative and quantitative data collection tools were analyzed and discussed together and quantitatively within the framework of embedded mixed method approach. Data collection tools of this study were "Earth-2" and "Earth and Day-Night Concepts Interview Protocol".

The findings of the study, demonstrated that all of the children had synthetic mental models regarding the shape of Earth and the day-night concepts. Findings about the shape of the Earth showed that the majority of the sample held flattened Earth model. Moreover, some children held ring Earth model which was also observed studies conducted in similar cultures and nearby geographies. Findings about the day and night cycle showed that a significant majority of children attributed day and night cycle to the movements of Sun and the limited number of children related it with the God.
\end{abstract}

Keywords: Earth, day-night cycle, mental models

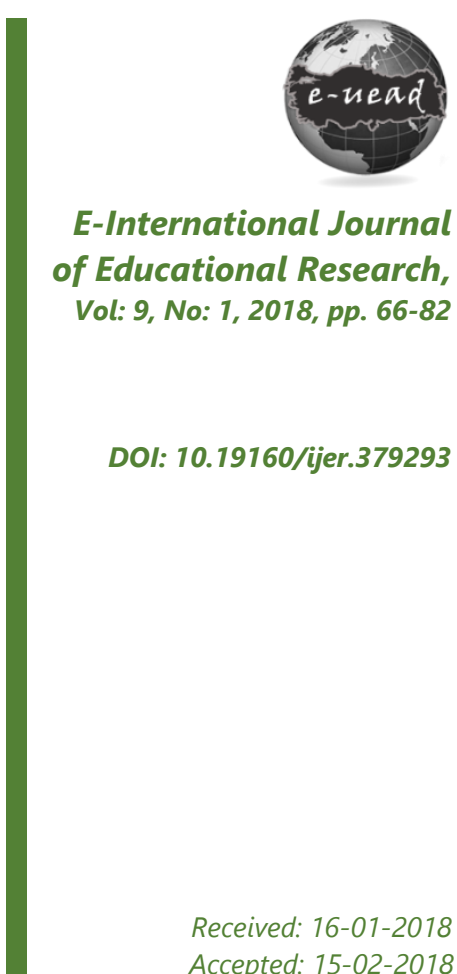

\section{Suggested Citation:}

Özgül, S.G., B. Akman \& M. Saçkes (2018). Children's Mental Models about the Shape of the Earth and Day-Night Concepts, , E-International Journal of Educational Research, Vol: 9, No: 1, 2018, pp. 66-82, DOI: 10.19160/ijer.379293

\footnotetext{
* This study was generated from the doctoral thesis of the first author (Sinem Güçhan Özgül) titled "The Effect of Inquiry Based Plays on Children's Perceptions of the Shape of the Earth and Day-Night Concepts.
} 


\section{EXTENDED ABSTRACT}

Problem: Children have inborn capabilities and endless motivation to search natural world and learn about it. Thus, children in their early years possess remarkably significant and various amounts of knowledge in different domains such as vocabulary, counting skills, reasoning and even psychology, physics and biology. These conceptual understandings of children about how natural world works are based on their observations and are shaped by their informal learning experiences. Recent studies state that there are differences between children's explanations derived from the synthesis of daily observations, cultural interactions, and the scientific ones. These alternative explanations of children have a notably meaningful impact on their scientific understandings and further school lives.

Many studies with children from different cultures reveal that children have problems in the sense of scientific explanations of astronomical phenomena. Pioneering studies on children's conceptual understandings about the shape of Earth and day-night cycle revealed three discriminating conceptual models (Appendix 1 and 2). These are; (1) Initial model, (2) Synthetic model, and (3) Scientific model. These models are frameworks underline children's conceptual understandings about the physical properties of Earth and day-night phenomena. Initial models are derived from daily observations and show no interaction with scientific knowledge. Besides, synthetic models are blended with everyday experiences and cultural/instructional information but still away from the scientific knowledge. Synthetic mental models are defined as consistent, change-resistant conceptual understandings within themselves. Scientific models consist of definitions including scientific truths and explanations. Many researchers use these models; tested and updated with different research methods and sample groups. These mental models have been taken into consideration in this study while investigating children's conceptual understandings. This study mainly aims to investigate 60-72 months old children's understandings about the shape of the Earth and day-night concepts.

Method: The sample of the study consists of 56 children (31 girls, 25 boys) aged between $60-72$ months attending the kindergarten in a city center located in the Northwestern part of Turkey. Within the aim of this study, the data obtained from qualitative and quantitative data collection tools are analyzed and discussed together and quantitatively within the framework of embedded mixed method approach. Data collection tools of this study are "Earth-2" and "Earth and Day-Night Concepts Interview Protocol". In the present study the reliability coefficient for the Earth-2 test was found to be .69. Interview protocol and Earth-2 test were administered to 56 children individually. While interviewing voice records, visual notes and photos of clay models were taken by the researcher. The answers given by the children to the test items and interview protocol and the models they generated are analyzed after converting qualitative data into quantitative with using the coding template developed by researchers.

Findings: Based on the results of the study, all of the children have synthetic mental models about the shape of Earth and day-night cycle. It should be kept in mind that all children were reported synthetically as conceptual understanding because all of them gave responses that showed synthetic or initial concepts in at least one of the interview, model building, model definition and Earth-2 test steps.

It is also possible to determine the synthetic conceptual understandings of these children about the shape of the earth in detail (Table 1). $91.1 \%(f=51)$ of the children have a flattened earth model, $5.34 \%(f=3)$ have a dual earth model, $1.78 \%(f=1)$ hollow sphere and $1.78 \%(f=1)$ donut earth model. 
When the findings are examined in detail (Table 4), it can be seen that the conceptual understandings of children about the day and night cycle are different from the scientific model which expresses "the world is turning around itself, and the sun illuminates the different sides of the world". The sun's hiding behind the moon or clouds and going down (sunset) are the most emerging concepts at all stages of the interview protocol. Six children from the sample group attributed the Day-Night cycle to God.

Discussion and Results: The results of this study suggest that children have alternative concepts that they have created by synthesizing scientific knowledge and daily observations about the shape of Earth and day-night cycle. Findings about the shape of the Earth show that the majority of the sample has flattened Earth model. Moreover, some children hold ring Earth model which was also observed studies conducted in similar cultures and nearby geographies Findings about the day and night cycle showed that a significant majority of children attributed the day and night cycle to the movements of Sun and the limited number of children relate it with the God.

The findings of this study suggest that developmentally appropriate teaching interventions and support should be provided to young children to facilitate the transformation of the alternative/synthetic conceptual models into the scientific ones. Inquiry-based learning cycles could be a suitable tool in targeting young children's alternative mental models. 


\section{EKLER}

Ek 1.

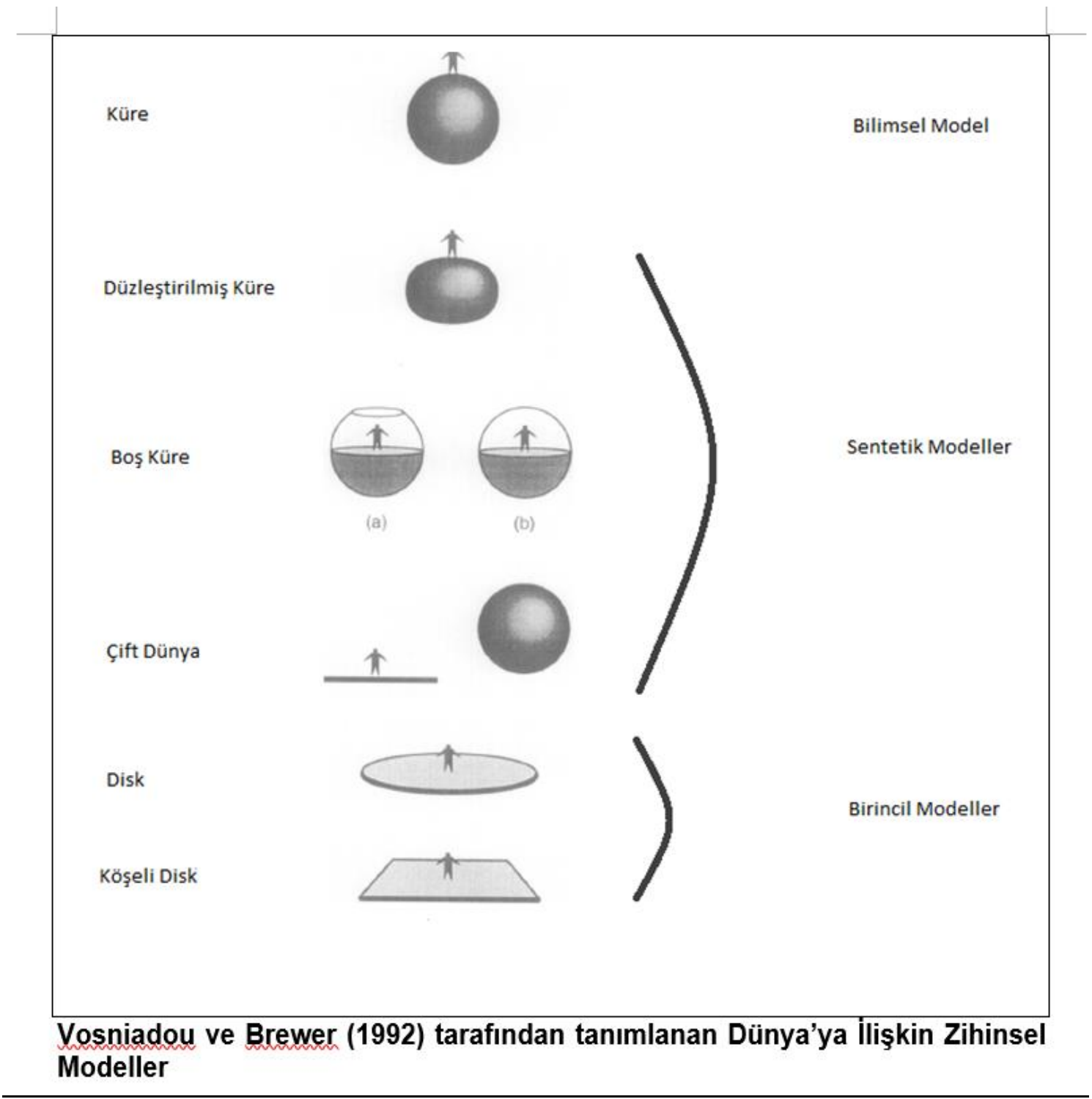


Birincil Zihinsel Modeller

1.

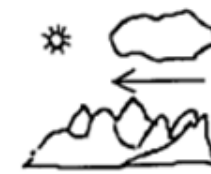

Gūneș bulutlar veya karanlık tarafından engellenmektedir.

4.

吢

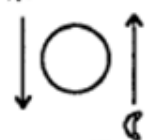

Gūneş ve ay dūnyanın farkl

taraflarında aşas̆ı ve yukarı

hareket etmektedir.

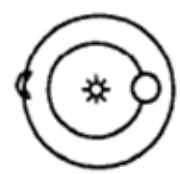

Dūnya ve ay her 24 saatte bir

güneşin çevresinde

dōnmektedir.

Bilimsel Zihinsel Mode

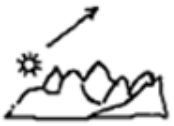

Güneş uzayın dışına

çıkmaktadır.

Sentetik Zihinsel Modeller

5.

.

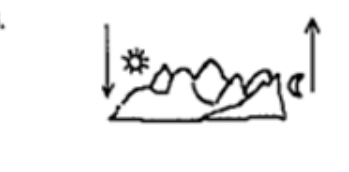

Gūneş ve ay aşağı ve yukarı hareket etmektedir.

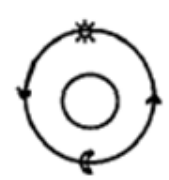

7. 凉

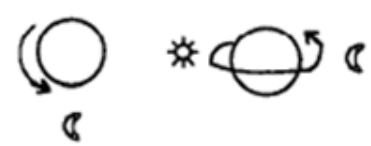

(a) veya (b)

Dūnya yukarı/aşağı veya

batıdan/doğuya dōnmektedir.

Gūneş ve ay zıt taraflarda

sabittir.

8. 栾

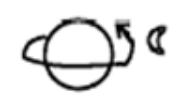

Dūnya batıdan doğuya

dōnmektedir. Gūneş sabittir

fakay ay dūnyanın etrafında

dōnmektedir.

Vosniadou ve Brewer (1994) tarafından tanımlanan Gece-Gündüz Oluşumuna ílişkin Zihinsel Modeller 